\title{
Publisher's Note: Eigenvalue Outliers of Non-Hermitian Random Matrices with a Local Tree Structure [Phys. Rev. Lett. 117, 224101 (2016)]
}

Izaak Neri and Fernando Lucas Metz

(Received 15 December 2016; published 5 January 2017)

DOI: 10.1103/PhysRevLett.118.019901

This Letter was published online on 23 November 2016 with an error in Eq. (4). Equation (4) should read as

$$
\lim _{\eta \rightarrow 0} i \eta \mathbf{G}_{n}\left(\lambda_{\text {isol }}-i \eta\right)=\left|r_{\text {isol }}\right\rangle\left\langle l_{\text {isol }}\right|+\mathcal{O}(\eta)
$$

The equation has been corrected as of 16 December 2016. The equation is incorrect in the printed version of the journal. 